NASA Technical Memorandum 101341

\title{
Photovoltaics for High Capacity Space Power Systems
}

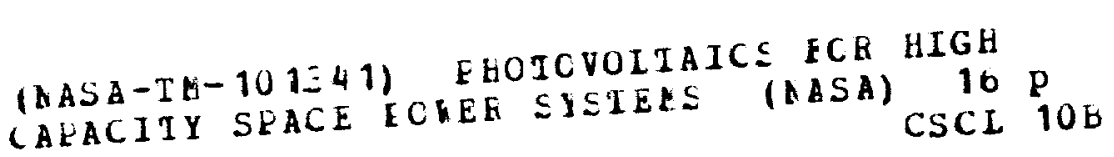
$63 / 20$
N89-10122

Unclas

0168450

Dennis J. Flood

Lewis Research Center

Cleveland, Ohio

Prepared for the

39th Annual Astronautical Congress of the International Astronautical Federation

Bangalore, India, October 8-15, 1988 



\title{
PHOTOVOLTAICS FOR HIGH CAPACITY SPACE POWER SYSTEMS
}

\author{
Dennis J. Flood \\ National Aeronautics and Space Administration \\ Lewis Research Center \\ Cleveland, Ohio 44135
}

\section{SUMMARY}

The anticipated energy requirements of future space missions will grow by factors approaching 100 or more, particularly as we establish a permanent manned presence in space. The advances that can be expected in solar array performance and lifetime, when coupled with advanced, high energy density storage batteries and/or fuel cells, will continue to make photovoltaic energy conversion a viable power generating option for the large systems of the future. The specific technologies required to satisfy any particular set of power requirements will vary from mission to mission. Nonetheless, in almost all cases the technology push will be toward lighter weight and higher efficiency, whether of solar arrays or storage devices. This paper will describe the content and direction of the current NASA program in space photovoltaic technology. The paper will also discuss projected system level capabilities of photovoltaic power systems in the context of some of the new mission opportunities under study by NASA, such as a manned lunar base, and a manned visit to Mars.

\section{INTRODUCTION}

The decade of the eighties has seen a rapid acceleration in the demand for more sophisticated technology in all aspects of the space program. Nowhere, however, is this trend more evident than in the field of space power system technology, where projected power requirements span the range from a few hundred watts to megawatts, with increased emphasis on high performance, reliability and extended lifetime. At the same time, there has been an increased awareness of the impact of life cycle costs on the total cost of a space mission, particularly as space missions become more "operational" in nature, as will be the case, e.g., for a manned space station. All of these factors, when coupled together, have spawned an intense interest in power generation using technologies which compete with photovoltaics - viz. nuclear and solar thermal systems - particularly when large power requirements are considered. Earlier studies by NASA have contended that the alternate, advanced technologies appear to provide substantial system benefits when compared to the solar array and energy storage technologies actually in flight at the time the studies were conducted (refs. 1 and 2). Photovoltaic power system technology has not remained static, however, with the result that new capabilities are beginning to emerge which make it much more competitive for future high capacity power applications. Succeeding sections of this paper will highlight the important advances that have been made, discuss their potential, and indicate what problems yet remain to be resolved before full confidence in the technology can be establi shed.

The anticipated energy requirements of future missions are illustrated in figure 1. Clearly, power system technology must address a wide range of power requirements and a variety of operating environments. Specific applicability 
of a given technology to any particular mission depends strongly on the exact nature of the mission, but there are certain system attributes for various mission subsets that can serve to focus an R\&T program. Table I contains a listing of some important mission subsets, a qualitative assessment of their associated power requirements, and the key attributes a given space power system should have to be useful there. The key attributes for each mission subset have been listed in relative priority order, with the caveat that the final priorities for an actual mission depend in a critical way on the outcome of system trade-off studies.

To assure the continued viability of solar energy for use in space it is imperative that space photovoltaic R\&T efforts provide not only improved technology for actual use on future missions, but also a sufficiently complete database of advanced technology options so that mission planners can make system trades with confidence. The latter is important to assure that advances in technology will result in net total system benefits that will have a real impact on mission planning and implementation. The desired system attributes listed for each of the mission subsets should serve as guides for future technology thrusts. At the cell level, for example, the most important technology thrusts are high efficiency and radiation tolerance. At the array level the important thrusts are low mass, high strength, durability, and in some cases, minimum storage volume.

High capacity power systems are loosely defined to be those required to deliver in excess of $25 \mathrm{kWe}$. Obviously there is a certain amount of arbitrariness in such a definition, but it is a useful reminder that there has been essentially no in-space experience with power levels above $25 \mathrm{~kW}$. (Skylab had been designed with $20 \mathrm{~kW}$, but provided only $12 \mathrm{~kW}$ on orbit because of a premature deployment and subsequent disablement of part of the array during the ascent phase.) In what follows we shall review some of the more important generic mission drivers, discuss the issues that arise as a result, and investigate the technological development required of space photovoltaics if it is to compete effectively with alternative power system approaches for use on future missions. Some attention will be given in this discussion to total system requirements. The intent is to develop the context within which space photovoltaic technology improvements must be pursued, and to display and evaluate more readily the potential impact on future mission capability that those technology improvements may have.

\section{MISSION DRIVERS}

\section{Lunar/Mars Applications}

While there are several possible future missions which will require power systems on the order of $25 \mathrm{kWe}$ or more, we will focus our initial discussion on two potential scenarios currently receiving a great deal of attention within NASA - the creation of a permanent human presence on both Mars and the moon. The establishment of permanently manned Mars or lunar bases represents a formidable challenge to a broad spectrum of space technologies. While all the technologies that will be required to sustain the evolution of such bases, from their initial establishment as outposts to their final manifestation as permanent, life-sustaining and productive habitats, are essential, the pacing technology for it all is the production of power. A new aspect of these scenarios is that the "mission" requirements are no longer fixed, but will evolve over 
time. It is now necessary to examine and develop a time-dependent set of requirements for the power system, and to put in place an adequately supported research and development program that is properly phased to produce the needed technology at the right time. The NASA Lewis Research Center, as lead center for space power for the NASA Office of Aeronautics and Space Technology (OAST) has taken the first steps in that direction with the implementation of a program in High Capacity Power, and the impending implementation of programs in Surface Power and Rover Power.

The preceding technology initiatives are the outgrowth of planning activities that have been conducted by OAST over the past few years, and which have culminated in the establishment of the Civil Space Technology Initiative (CSTI), and the Pathfinder Program. The High Capacity Power program is an element of CSTI, and the Surface Power and Rover Power programs are elements of Pathfinder.

While the definition of a complete set of time-dependent requirements is an unfinished task, an understanding of key issues has been developed to help guide the focussed technology programs mentioned above. Discussion will be limited to the lunar scenario, although essentially the same considerations would apply to the case for Mars. Technologies intended for application on the lunar surface will be driven by mass considerations, primarily because of the high cost of payload delivery to the moon. Even if the assumption is made that low operational cost cargo vessels will be available for transit from low earth orbit (LEO) to the moon, there will still be a high cost for delivery to LEO which must be considered. For comparison purposes the cost can be represented by a payload mass multiplication factor which takes into account the total launch mass required to deliver the intended lunar base elements to LEO. Although a universally agreed-on value for such a multiplier does not exist, primarily because the exact nature of future heavy-lift launch capabilities is not known, a value of five has been assumed for this discussion, along with an assumed heavy lift vehicle (HLV) payload capability of $91000 \mathrm{~kg}(200000 \mathrm{lb}$ ) to LEO. Such assumptions are not unreasonable with respect to future launch systems. No further justification for using them will be provided except to point out that doing so allows a quantitative comparison of power system alternatives in terms of "operational" impact - the number of launch vehicles required to deliver the system elements to LEO for subsequent transport to the lunar surface.

The key figure of merit for a photovoltaic array is the power per unit mass in watts per $\mathrm{kilogram}$, or $\mathrm{W} / \mathrm{kg}$. For a storage system the appropriate figure of merit is the amount of available energy per unit mass in watt hours per $\mathrm{kilogram}$, or $\mathrm{Wh} / \mathrm{kg}$. The advanced system uses an ultralightweight photovoltaic array and an advanced hydrogen-oxygen ( $H-O$ ) regenerative fuel cell (RFC) for storage. The figures of merit for both sub-systems are listed in table II. Table III compares the system mass for a state-of-the-art photovoltaic generation/battery storage power system sized to deliver $100 \mathrm{~kW}$ to a lunar base with that projected for an advanced version of such a system. Two cases are considered for the 2 week lunar night: a 100 percent duty cycle and a 20 percent duty cycle. Also shown is the mass saved in delivering the advanced system to LEO, along with the resulting number of HLV (Heavy Lift Vehicle) launches saved, under the assumptions given above. The table provides compelling evidence that there is a substantial payoff to be had in developing the advanced PV/RFC technology, particularly when placed in the "operational" context of the weight saved at LEO. 
Figure 2 provides a more graphic comparison between the mass of the SOA PV/battery system, the PV/RFC system, and the SP-100 nuclear power system currently under joint development by NASA, DOE, and DOD. As can be clearly seen, the advanced PV/RFC technology has the potential to reduce the mass of a $100 \mathrm{kWe}$ lunar surface power system which uses SOA technology by more than a factor of 45 , to a value of less than 2.5 percent of the mass of the latter. The SP-100 system, even though projected to be lighter than the advanced PV/RFC system by nearly a factor of 10, will only save approximately another 2 percent of the SOA system mass, assuming that a 100 percent night duty cycle is desired. The long lunar night is clearly the major issue in determining the mass of the lunar base PV/electrochemical storage system. The key feature that allows such a large mass reduction is that the stored energy in an advanced regenerative fuel cell system is in the form of gaseous reactants stored in advanced, lightweight high pressure tanks, with the result that the RFC figure of merit can approach $1000 \mathrm{Wh} / \mathrm{kg}$, a factor of 4 or 5 better than projected for advanced batteries, and a factor of more than 60 better than SOA batteries $\left(\mathrm{NiH}_{2}\right.$, e.g.) (ref. 3).

\section{Orbit Transfer Applications}

Figure 3 shows a comparison of projected specific power for a space nuclear power system (the SP-100), an advanced solar dynamic power system, an IOC space station photovoltaic system design, and advanced silicon photovoltaic power system technology (ref. 1). The precipitous drop in solar array performance at the mid altitudes is the result of radiation damage incurred while orbiting in the van Allen belts. If not improved, such behavior all but precludes the use of solar arrays to provide power for any mission that must operate there, such as an electric propulsion orbit transfer vehicle. Photovoltaic power systems, if they are to compete effectively for this application, which may require power from tens of kilowatts to several megawatts, will need technology which significantly reduces radiation damage degradation at very high fluence levels. Advanced array technology must be developed which will allow the power system to spend from 3 to 6 months spiraling through the van Allen belts either without losing power, or with the ability to recover from any degradation that has occurred. In addition, in many such mission scenarios it appears desirable that the array be able to emerge with a minimum specific power of $100 \mathrm{~W} / \mathrm{kg}$ after each one way trip. Storage for 100 percent duty during eclipse is not necessarily required, since the OTV could be allowed to coast during that time. Lightweight, advanced photovoltaic cell and array technology must be developed that either provides better radiation resistance, or enables in-flight annealing, or a combination of both to meet the performance goal. Clearly those are ambitious technology challenges. The payoff is enormous, however, since it could open the way to multimegawatt applications of photovoltaics in space. A later section of this paper will outline some of the possible approaches for meeting the performance requirements set forth above.

\section{Advanced Space Station Applications}

Specific power is not the only driver for high capacity power systems, however. As is well known, total mission costs have become a major concern for the NASA space station, and a significant contributor to such costs is that of reboosting the station periodically in its orbit. Reboost becomes necessary because of the orbit decaying drag produced by the residual atmosphere present 
at projected space station altitudes. For this reason it becomes important to minimize the cross-sectional area of the station, since the drag forces are directly proportional to it. Here, too, photovoltaic power systems face serious competition, this time because of the physical size of a conventional silicon solar cell array. Early space station system studies done internally for NASA showed that total mission costs of a space station equipped with a flat plate, single crystal silicon solar cell array would be excessive because of the continuing cost of reboost fuel resupply. As a result, the NASA space station program elected to undertake development of a solar dynamic power source, which, by virtue of its presumably higher efficiency and lower drag area, is projected to have more favorable life cycle costs than a photovoltaic system. If photovoltaic systems are to compete effectively in this arena, improved photovoltaic/electrochemical storage systems are needed with orbital efficiencies approaching, and perhaps exceeding, 20 percent. Clearly, a significant fraction of the advance must come from more efficient, higher energy density storage technology. Nonetheless, arrays with area specific powers approaching $300 \mathrm{~W} / \mathrm{m}^{2}$ must become available at reasonable cost to be able to challenge the competing technologies effectively. Again, we shall deal with the question of what sort of PV technology developments are needed to achieve such performance in a later section of the paper.

\section{Interplanetary Applications}

An issue developing in the space science community at the present time is that of our ability to perform deep space missions. Previous missions have been able to use radioisotope thermal generators, or RTG's, to provide payload power for journeys beyond Mars. Although such systems are heavy, typically 3 to $5 \mathrm{~W} / \mathrm{kg}$, they are compact, and can be located at the center of mass of the spacecraft. At issue is the continuing availability of such power sources during the next decade and beyond, particularly in the face of growing costs and reduced fuel element supplies. Although not suitable for all such missions, photovoltaic power sources have the potential to meet some of the needs in this mission class. Figure 4 is a plot of very simple estimates of advanced technology specific power versus distance from the sun ( 1 au = 1 earth radius (mean) from the sun) for several competing power systems. An ultralight solar array at $300 \mathrm{~W} / \mathrm{kg}$ at the earth's orbit could, in principal, provide power even in the vicinity of Saturn and be competitive with RTG's. A great deal of detail has been left out of this comparison, and would need to be investigated - such things as environmental interactions, low temperature, low intensity solar cell operation, array survivability and operability, and so on. Although there is no mission push for such technology at the present time, demonstration of key elements of it would help to make it an available alternative for future consideration.

\section{NASA Space Photovoltaic Research}

The vast majority of space activities from now through the first decade of the 20th century, whether commercial, civilian, or military, will have power requirements in the range from a few hundred watts up to 20 or $30 \mathrm{~kW}$. The key feature is that there will be hundreds of such missions, including interplanetary science, earth observation, and communication (both commercial and military), and as a result hundreds of kilowatts to megawatts of space power will be needed in that timeframe. Clearly it will become imperative to improve 
the capability and lower the cost of future space power systems, no matter what the conversion technology. Moreover, it is also probable that essentially all such systems will be photovoltaic power systems, particularly for earth orbiting applications such as communication satellites and so on. It therefore also becomes imperative to develop higher efficiency, lower cost, longer life solar cells and arrays. In particular, new, high efficiency, radiation hard solar cells will be necessary to be able to sustain the desired levels of space activity envisioned. A leading candidate in that regard is the InP homojunction cell, which recently has achieved nearly 19 percent in the laboratory (ref. 4). The full development of this cell type, and others like it yet to be discovered, will have a significant impact on the cost and capability of future space activity. Other cell types with the potential for major impact are multiple bandgap cells, which could make 30 percent AMO conversion possible, at least under modest concentration (100X, or so), and thin ( $5 \mu \mathrm{m})$ GaAs cellis, which would enable ultrahigh specific power arrays with good radiation resistance. Also of interest are certain of the thin film solar cells, such as amorphous silicon and copper indium diselenide. Although of lower efficiency than single crystal solar cells, they have shown evidence of radiation hardness which would make their lower efficiencies acceptable in many cases, provided they can be made to exceed 10 percent AMO. Major barriers which must be overcome include not only low efficiency, but also the stability of the materials. If such cells are successfully developed, however, they could usher in a new era of low cost space photovoltaic power system technology as never before envisioned. The paragraphs that follow will discuss briefly some specific cell technologies and issues, and relate them to the system level issues described above.

\section{Indium Phosphide Cell Research}

Figure 5 shows a plot of calculated ideal efficiency as a function of bandgap in the AMO solar spectrum (ref. 5). The locations of the bandgaps of Si, GaAs and InP are shown on the figure. Reason for the interest shown in GaAs by the space community is self-evident: it has a higher theoretical efficiency than silicon. An important property not depicted by this curve, however, is the efficiency of a solar cell after exposure to the naturally occurring charged particle radiation found in the space environment (primarily trapped electrons and protons, and solar flare protons). Calculations predicting that behavior are difficult to make, with the result that any new cell material and/or design must undergo radiation testing to determine its spaceworthiness. Such testing is usually done in ground-based facilities, since the cost of spaceflight testing and verification is extremely expensive, and opportunities are limited. However, ground-based experiments suffer from some uncertainty because it is simply not possible to duplicate the particle and energy distribution that may be encountered at various orbits and at various times. Only after years of effort has it become possible to refer to an equivalent radiation dose for silicon solar cells using $1 \mathrm{MeV}$ electrons from an accelerator. For example, it is now accepted that the accrued damage in a silicon solar cell after exposure in an accelerator to a $1 \mathrm{MeV}$ electron fluence of $3 \times 10^{14} \mathrm{~cm}^{-2}$ is equivalent to that acquired after seven years in geosynchronous orbit with a $250 \mu \mathrm{m}$ coverglass on the cell (ref. 6).

It is also common practice to quote the behavior of other cell types after exposure to the same laboratory fluence, so that initial performance comparisons can be made. The uncertainties caused by this approach can only be 
resolved by spaceflight testing coupled with extensive cataloging of laboratory irradiation results. With the preceding caveat, figure 6 depicts the projected behavior of InP, GaAs, and silicon cells as a function of orbit altitude (ref. 7). The comparison is made between specific powers for the same initial array output before exposure. The difference in BOL specific powers is caused by the reduced array area (and hence reduced balance-of-system mass) needed for higher efficiency solar cells. All array masses are based on an advanced, lightweight array concept, the technology for which is currently being developed in the NASA PV program (ref. 8). The BOL efficiencies are measured numbers for $S i$ and $G a A s$, and a predicted value of 20 percent for InP. As the figure shows, a lightweight InP array should have superior performance compared to either of the other two materials. Equally important, such an InP array will have a specific power in the radiation belts that is a factor of 10 better than the best solar array that has been flown to date. As mentioned, actual efficiencies in InP (AMO) are near 19 percent (ref. 4). Figure 7 summarizes the situation. InP cells are in the very early stages of their development. Based on our experience with GaAs and $\mathrm{Si}$, there is little reason to doubt that 20 percent $A M O$ efficiencies can be achieved.

A very interesting application of InP may well be in a concentrator array, with the cell operating temperature kept above $100^{\circ} \mathrm{C}$. Figures $8(\mathrm{a})$ and (b) show why. Complete annealing of electron-induced radiation damage has been observed in early InP cells at temperatures slightly above $100^{\circ} \mathrm{C}$ (refs. 9 and 10). If similar behavior can be maintained in high efficiency cells, and shown to apply to proton damage as well, the possibility exists to produce high efficiency, high specific power, radiation hard solar arrays for use in high radiation environments. Projected specific power for such arrays range as high as $100 \mathrm{~W} / \mathrm{kg}$, and with advanced storage capabilities, radiation insensitive earth orbiting system specific powers of $50 \mathrm{~W} / \mathrm{kg}$ are a possibility. Realization of such goals would make photovoltaic power systems strong competitors to the other technologies now under investigation.

\section{GaAs and Other Advanced III-V Solar Cells}

The list of advanced solar cell candidates currently under investigation for space use is quite extensive, and cannot be discussed in detail here. Of interest, however, is the development of the silicon point contact solar cell, for two reasons (ref. 11). The first is the cell itself, which, with its high efficiency, could find use in radiation benign missions, or perhaps in a system which provides suitable protection from space radiation, such as in a concentrator array. Clearly, the sensitivity of that cell to radiation damage is a major issue. The second is whether that design could be utilized in any of the III-V cell materials, such as GaAs and InP. Weizer and Godlewski have shown that efficiencies exceeding 25 percent AMO are possible at one sun in such a cell, based on material and operating parameters already achieved in laboratory devices (ref. 12). Developing such a cell for use in concentrated sunlight could well result in efficiencies above 28 percent AMO. Again, a key issue to be addressed is the radiation tolerance of such a device, since its successful operation is critically dependent on maintaining diffusion lengths long enough to provide good current collection. A projected design calls for approxi-
mately 1 percent coverage by the dot junction area to achieve high open circuit voltage. If the dots are $1 \mu \mathrm{m}$ in diameter, diffusion lengths on the order of $100 \mu \mathrm{m}$ will be required. It is encouraging that such numbers have been observed in very pure, i ightly doped material (ref. 13). Also critical is the 
development of a good passivation technique for the GaAs surface regions between the junction dots. Much work remains to be done on this cell before it is a practical reality, but its potential for improving the applicability of photovoltaics for space missions makes it an important technology to investigate.

Development of a super high efficiency GaAs cell has another interesting implication. Figure 9 contains plots of the efficiency contours of a two junction tandem solar cell in a two terminal and a four terminal configuration (ref. 14). The bottom cell bandgap is the ordinate in each plot, and the top cell bandgap is the abscissa. The calculation is for $100 \times$ AMO, and a cell temperature of $80^{\circ} \mathrm{C}$. As with the terrestrial spectrum, the optimum bandgaps are near 1.75 and $1.1 \mathrm{eV}$ and as the figure shows, an ideal efficiency of 35 percent AMO is expected. In this case the top cell must have about 20 percent conversion efficiency, with the remainder coming from the $1.1 \mathrm{eV}$ bottom cell.

The figure also makes clear the desirability of using four instead of two terminals: there is a wider range of acceptable bandgaps for the former case. of even more importance, a four terminal cell will have a greater tolerance for radiation-induced damage. The reason is straightforward - a two terminal cell requires current matching between top and bottom cell for optimum performance. Anything, such as radiation damage, which causes a mismatch will lead quickly to degraded total performance. In a four terminal configuration, however, the two cells are electrically independent of each other so that the effect will not be compounded as rapidly. Complexity will increase at the array level somewhat because essentially two power conditioning circuits must be employed, but the presumption is that the increased performance will be worth the extra effort. Also of interest is the performance that might be achieved by combining a dot junction GaAs concentrator cell with a slightly lower bandgap bottom cell of, e.g., InGaAs. A combination of full surface area junctions could well exhibit 30 percent efficiency under concentration, and output should be enhanced by the dot geometry to something well in excess of that. Even assuming that practical efficiencies require discounting the calculations by a few percentage points, efficiencies in the low- to mid-30 percent range could be feasible.

\section{Space Concentrator Arrays}

A key element in much of what has been discussed above is the use of concentrated sunlight for space power systems. Properly designed concentrator arrays can provide substantial benefits for space power systems in terms of radiation protection and increased efficiency, and there is a major development program underway at the present time by the Air Force to demonstrate such technology (ref. 15). As presently envisioned, such arrays offer no improvement in specific power. They will be less than $30 \mathrm{~W} / \mathrm{kg}$, making them comparable to currently flying planar arrays. Meeting the space power system performance goals outlined earlier in this paper will require the development of space-qualified, lightweight, low cost, higher efficiency, refractive optical elements, and low mass, high strength array structures. The increased optical efficiency of a refractive element compared to a double reflecting element is an enabling factor for array area specific powers approaching $300 \mathrm{~W} / \mathrm{m}^{2}$, and power to mass ratios approaching $100 \mathrm{~W} / \mathrm{kg}$. However, the burden of radiation resistance will still be a major cell issue, and is the reason for considering InP cells in this context. The degree of shielding provided by an advanced concentrator 
array will most likely be lower than that envisioned for some of the current reflector designs, which rely on heavy optical elements for shielding. The space survivability of materials suitable for making such lenses is a major issue yet to be addressed, but the potential payoff in improved system performance is significant.

\section{CONCLUSION}

We have reviewed briefly the nature of the requirements that must be addressed for the successful continued application of photovoltaic power generation in space. The issues are challenging, but overcoming them should provide significant new capabilities for a variety of future space missions. 


\section{REFERENCES}

1. Brandhorst, H.W. Jr., Juhasz, A.J., and Jones, B.I., "Alternative Power Generation Concepts for Space, "Proceedings of the 5 th Conference on Photovoltaic Generators in Space, ESA-SP-267, W.R. Burke, ed., European Space Agency, Paris, France, 1986, pp. 13-19.

2. Nored, D.L., and Bernatowicz, D.T., "Electrical Power System Design for the U.S. Space Station," Toward Technology Breakout in Energy Conversion (2lst IECEC), Vol. 3, American Chemical Society, Washington, D.C., 1986, pp. 1416-1422. (NASA TM-88824).

3. Brinker, D.J., and Flood, D.J., "Advanced Photovoltaic Power System Technology for Lunar Base Applications," Lunar Bases and Space Activities of the 21 st Century. W.W. Mendel, ed., Lunar and Planetary Institute, Houston, TX, 1988 (to be published). (NASA TM-100965).

4. Keavney, C., "InP Shallow Homojunction Solar Cells," Space Photovoltaic Research and Technology 1988, NASA CP-, 1988 (to be published).

5. "Solar Cells-Outlook for Improved Efficiency," National Research Council, National Academy of Sciences, Washington, D.C., 1972. (NASA CR-127234).

6. Tada, H.Y.; Carter, J.R.; Anspaugh, B.E.; and Downing, R.G., eds., "Solar Cell Radiation Handbook," JPL-PUB-82-69, Jet Propulsion Lab, California Institute of Technology, Pasadena, CA, Nov. 1982.

7. Weinberg, I.; and Brinker, D.J., "Indium Phosphide Solar Cells," Toward Technology Breakout in Energy Conversion (21st IECEC), Vol. 3, American Chemical Society, Washington, D.C., 1986, pp. 1431-1435. (NASA TM-87315).

8. Scott-Monck, J., "Progress in Developing High Performance Solar Blankets and Arrays," Space Photovoltaic Research and Technology 1982: High

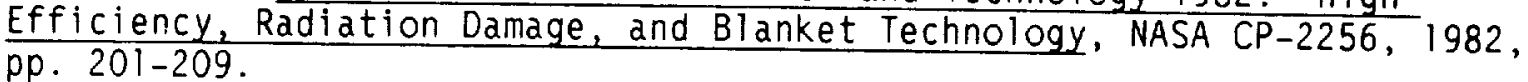

9. Yamaguchi, M.; Uemura, C.; and Yamamoto, A., "Radiation Damage in InP Single Crystals and Solar Cells," Journal of Applied Physics, Vol. 55, no. 6, Mar. 15, 1984, pp. 1429-1436.

10. Yamaguchi, M., Ando, K., Yamamoto, A., and Uemura, C., "Raman Spectroscopy of PtSi Formation at the Pt/Si(100) Interface," Applied Physics Letters, Vol. 44, no. 4, Feb 15, 1984, pp. 431-432.

11. Swanson, R.M., Beckwith, S.K., Crane, R.A., Eades, W.D., Kwark, Y.H., Sinton, R.A., and Swirhun, S.E., "Point-Contact Silicon Solar Cells," IEEE Transactions on Electron Devices, Vol. ED-31, no. 5, May 1984, pp. 661-664.

12. Weizer, V.G., and Godlewski, M.P., "Effect of Solar-Cell Junction Geometry on Open-Circuit Voltage," Journal of Applied Physics, Vol. 57, no. 6, Mar. 15, 1985, pp. 2292-2294. 
13. Nelson, R.J., "Measurement of $100 \mu \mathrm{m}$ Minority Carrier Diffusion Lengths in p-GaAs by' a New Photoluminescence Method," Gallium Arsenide and

Related Compounds 1978, C.M. Wolfe, ed., Institute of Physics Conference Series No. 45, Bristol, England, 1979, pp. 256-262.

14. Fan, J.C.C. and Palm, B.J., "Optimal Design of High Efficiency

Single-Junction and Tandem Concentrator Space Cells at $80^{\circ} \mathrm{C}$ and 100 SUNS," Space Photovoltaic Research and Technology 1983, NASA CP-2314, 1983, pp. 120-127.

15. Geis, J., "The Air Force Concentrating Photovoltaic Array Program," Space Photovoltaic Research and Technology 1986, NASA CP-2475, 1986 , pp. $111-118$.

TABLE I. - NASA SPACE MISSION SUBSET

\begin{tabular}{|c|c|c|}
\hline Mission subset & Power level & System attributes \\
\hline $\begin{array}{l}\text { Unmanned near earth } \\
\text { (LEO, HEO, GEO) and } \\
\text { planetary applications }\end{array}$ & Low to intermediate & $\begin{array}{l}\text { Low mass, } \\
\text { long life }\end{array}$ \\
\hline Space station & High & $\begin{array}{c}\text { Minimum area, } \\
\text { low mass, } \\
\text { low cost }\end{array}$ \\
\hline GEO platform & Intermediate & $\begin{array}{l}\text { Long life, } \\
\text { Tow mass }\end{array}$ \\
\hline $\begin{array}{l}\text { Lunar base, } \\
\text { manned planetary }\end{array}$ & $\begin{array}{l}\text { Intermediate to high } \\
\text {. }\end{array}$ & $\begin{array}{l}\text { Low mass, } \\
\text { portability, } \\
\text { long life }\end{array}$ \\
\hline $\begin{array}{l}\text { Electric propulsion } \\
\text { orbit transfer (OTV) }\end{array}$ & $\mathrm{High}$ & $\begin{array}{l}\text { Reusability, } \\
\text { minimum area, } \\
\text { low mass }\end{array}$ \\
\hline
\end{tabular}

TABLE II. - FIGURE OF MERIT COMPARISONS FOR PHOTOVOLTAIC/ELECTROCHEMICAL TECHNOLOGY OPTIONS

\begin{tabular}{|l|c|c|}
\hline & State of the art & Advanced \\
\hline Array & $66 \mathrm{~W} / \mathrm{kg}$ & $\begin{array}{c}300 \mathrm{~W} / \mathrm{kg} \\
\text { ultralightweight }\end{array}$ \\
Storage & $\begin{array}{c}14 \mathrm{Wh} / \mathrm{kg}, \\
\mathrm{NiH} \text { battery }\end{array}$ & $\begin{array}{c}1000 \mathrm{Wh} / \mathrm{kg}, \\
\mathrm{H}-0 \mathrm{RFC}\end{array}$ \\
\hline
\end{tabular}

TABLE III. - COMPARISON OF CURRENT AND ADVANCED PHOTOVOLTAIC POWER SYSTEMS FOR A MANNED LUNAR BASE

\begin{tabular}{|c|c|c|c|c|c|}
\hline $\begin{array}{c}\text { Power level, } \\
\text { kWe }\end{array}$ & $\begin{array}{c}\text { Night } \\
\text { duty } \\
\text { cycle, } \\
\text { percent }\end{array}$ & $\begin{array}{c}\text { SOA } \\
\text { PV/BATT, } \\
\text { mass, } \\
\mathrm{kg}\end{array}$ & $\begin{array}{c}\text { Advanced } \\
\text { PV/RFC } \\
\text { mass, } \\
\mathrm{kg}\end{array}$ & $\begin{array}{c}\text { Weight } \\
\text { saved } \\
\text { at LEO, } \\
\mathrm{kg}\end{array}$ & $\begin{array}{c}\text { HLV } \\
\text { launches } \\
\text { saved }\end{array}$ \\
\hline 100 & 100 & 1680000 & 34500 & 7910000 & 87 \\
100 & 20 & 336420 & 7133 & 1580000 & 17 \\
\hline
\end{tabular}




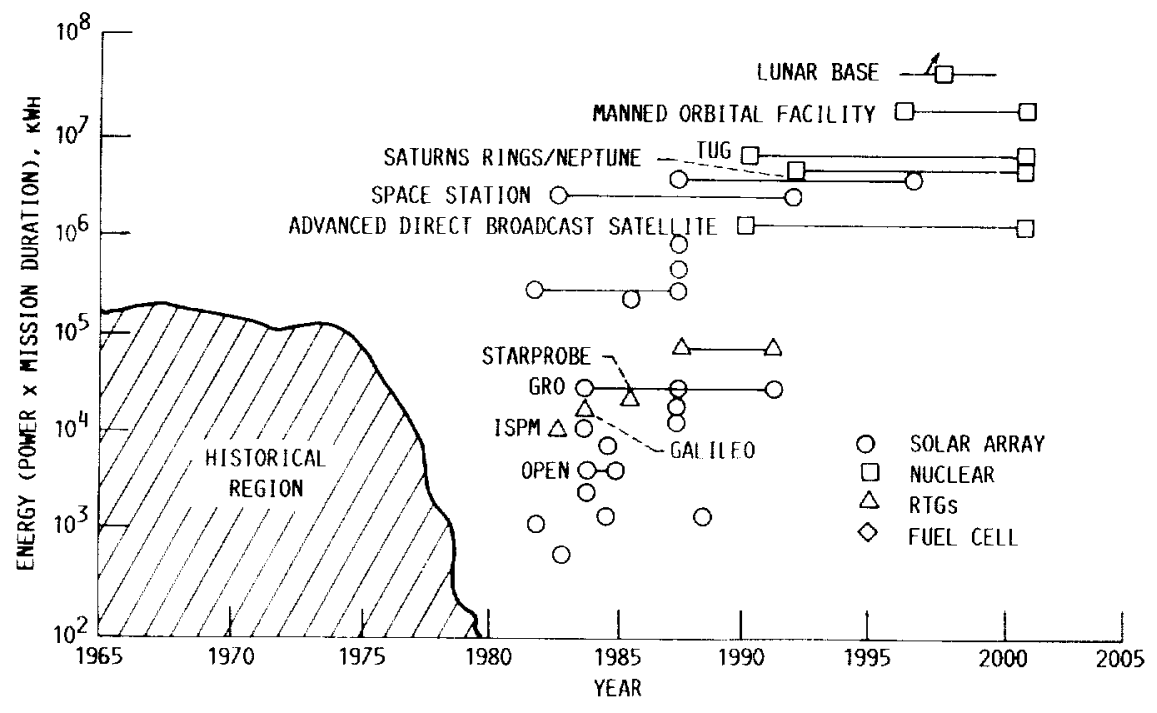

FIGURE 1. - FUTURE SPACE ENERGY DEMANDS.

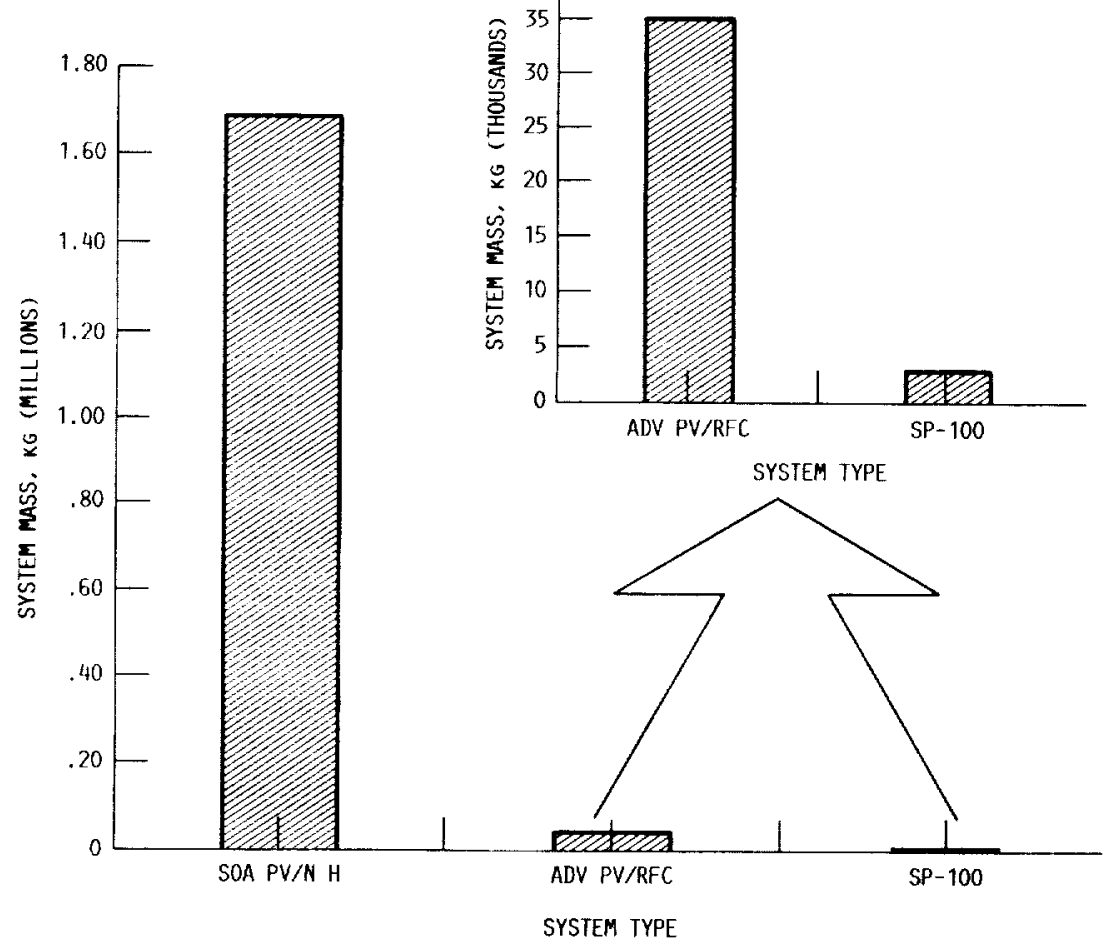

FIGURE 2. - COMPARISON OF PROJECTED POWER SYSTEM MASSES FOR A 100-KWE LUMAR BASE, 2-MEEK STORAGE. 
NUCLEAR ADVANCED TECHNOLOGY POTENTIAL. $100 \mathrm{~W} / \mathrm{KG}$

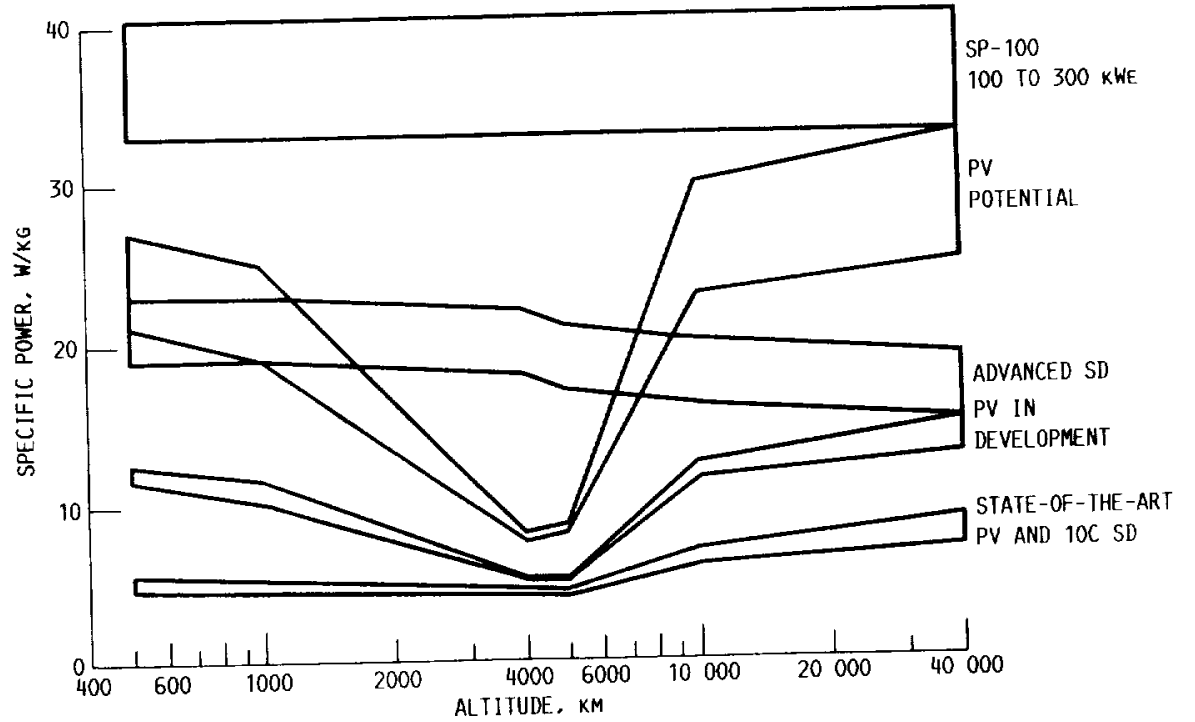

FIGURE 3. - SPECIFIC POWER COMPARISONS FOR SILICON PHOTOVOLTAIC SYSTEMS. ADVANCED SOLAR DYNAMIC AND NUCLEAR SYSTEMS. 5-YEAR LIFE.

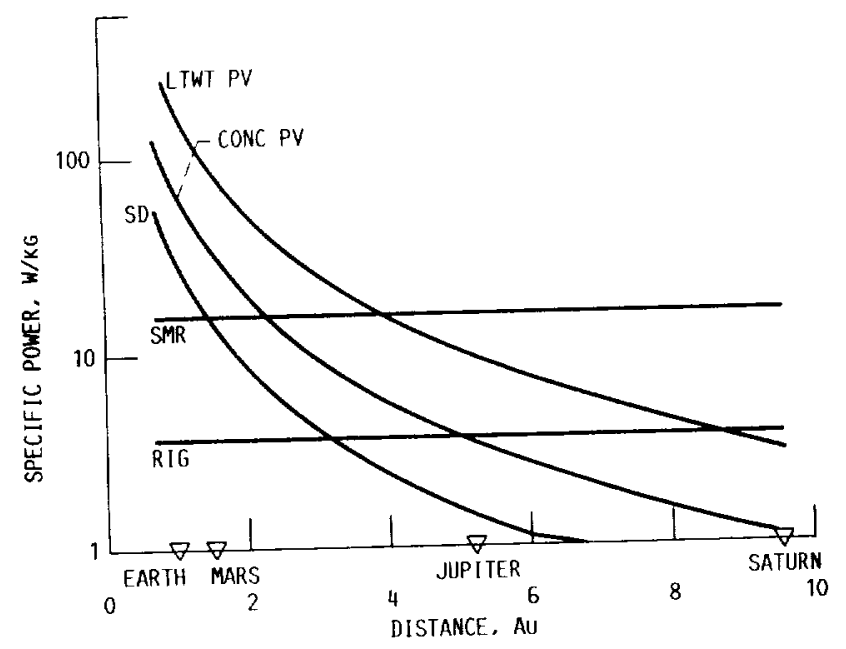

FIGURE 4. - PROJECTED SPECIFIC POWER COMPARISON FOR ADVANCED POWER SYSTEMS: LIGHTWEIGHT PHOTOVOLTAIC

(LTWTPV): CONCENTRATOR PHOTOVOLTAIC (CONC. PV): SOLAR DYNAMIC (SD): ADVANCED SMALL NUCLEAR REACTORS (SMR); AND RADIOISOTOPE THERMAL GENERATORS (RTG).

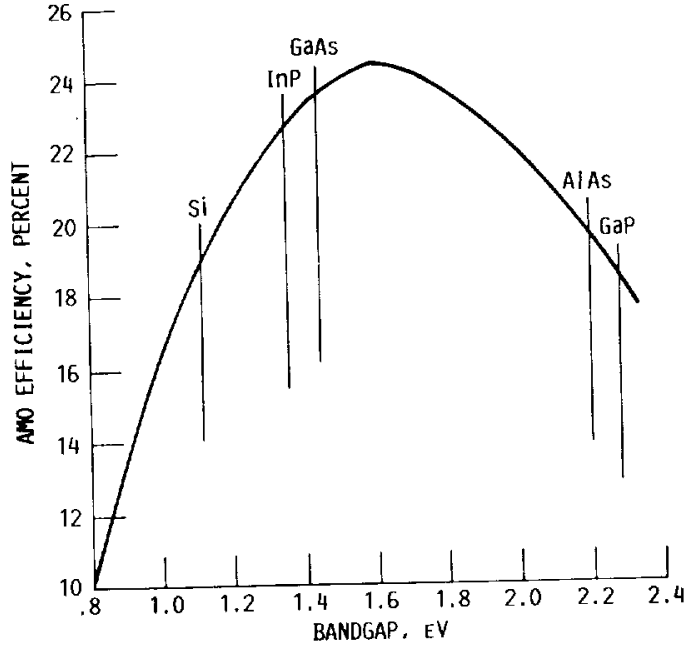

FIGURE 5. - EFFICIENCY VERSUS BAMDGAP AT AMO. 


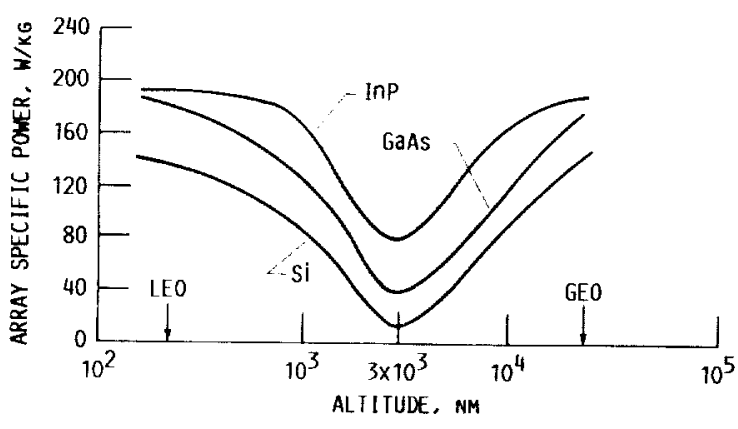

FIGURE 6. - COMPARISON OF SOLAR ARRAY CALCULATED OUTPUT AS A FUNCTION OF ORBIT ALTITUDE, BASED ON 1 MEV ELECTRON EQUIVALENT FLUENCES. TIME IN ORBIT $=7$ YEARS, CIRCULAR ORBIT, $30^{\circ}$ INCLIMATION, $\mathrm{T}=60^{\circ} \mathrm{C}$.

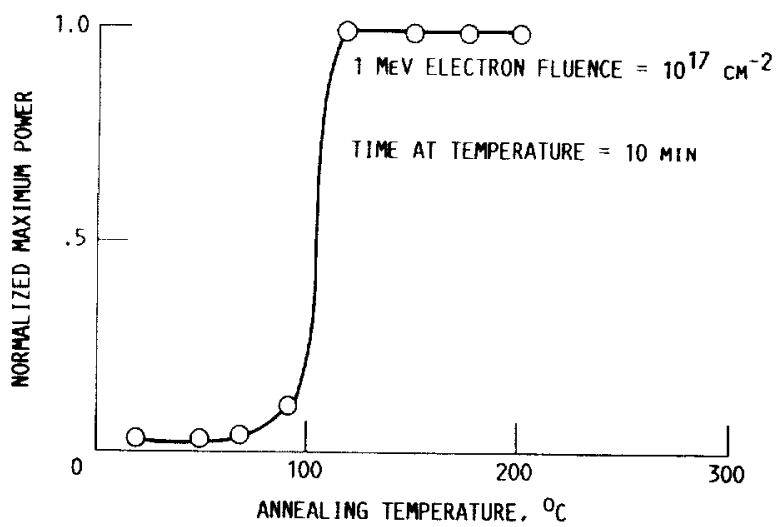

(a) RADIATION DAMAGE REMOVAL IN INP.

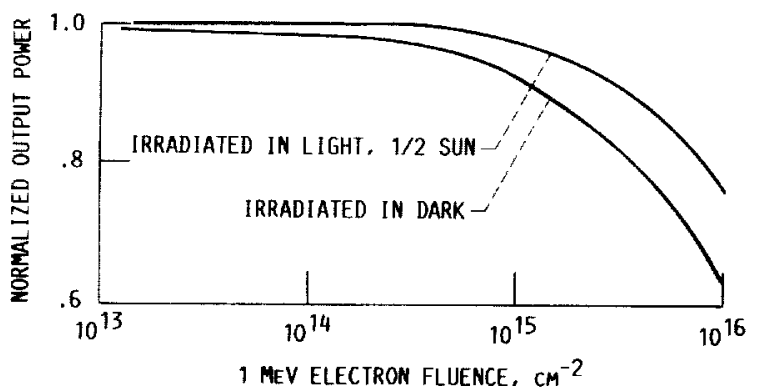

(b) CONTINUOUS ANMEALING UNDER ILLUMINATION.

FIGURE 8. - ANNEALING EFFECTS IN INP.

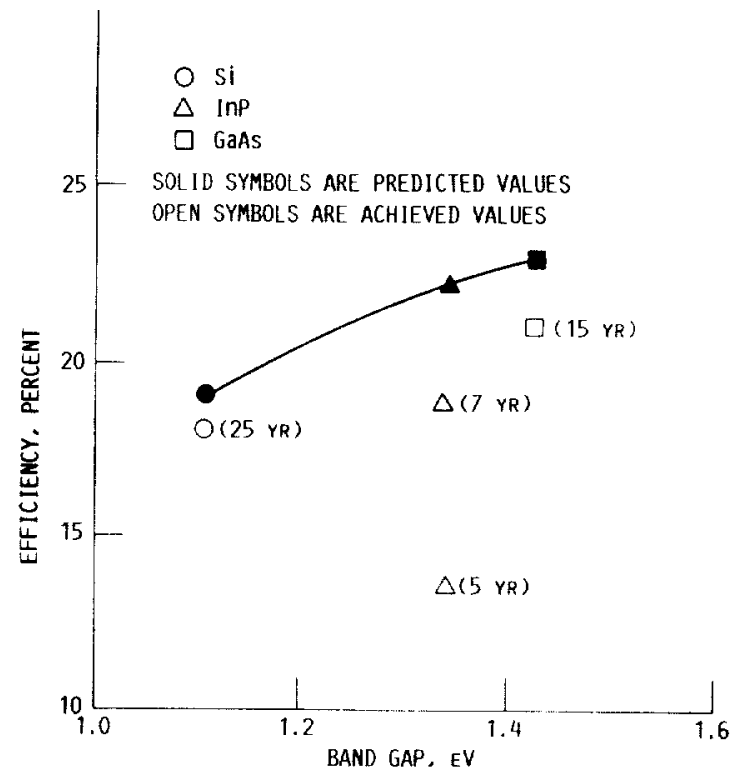

FIGURE 7. - PREDICIED AND ACHIEVED AMO EFFICIENCIES.

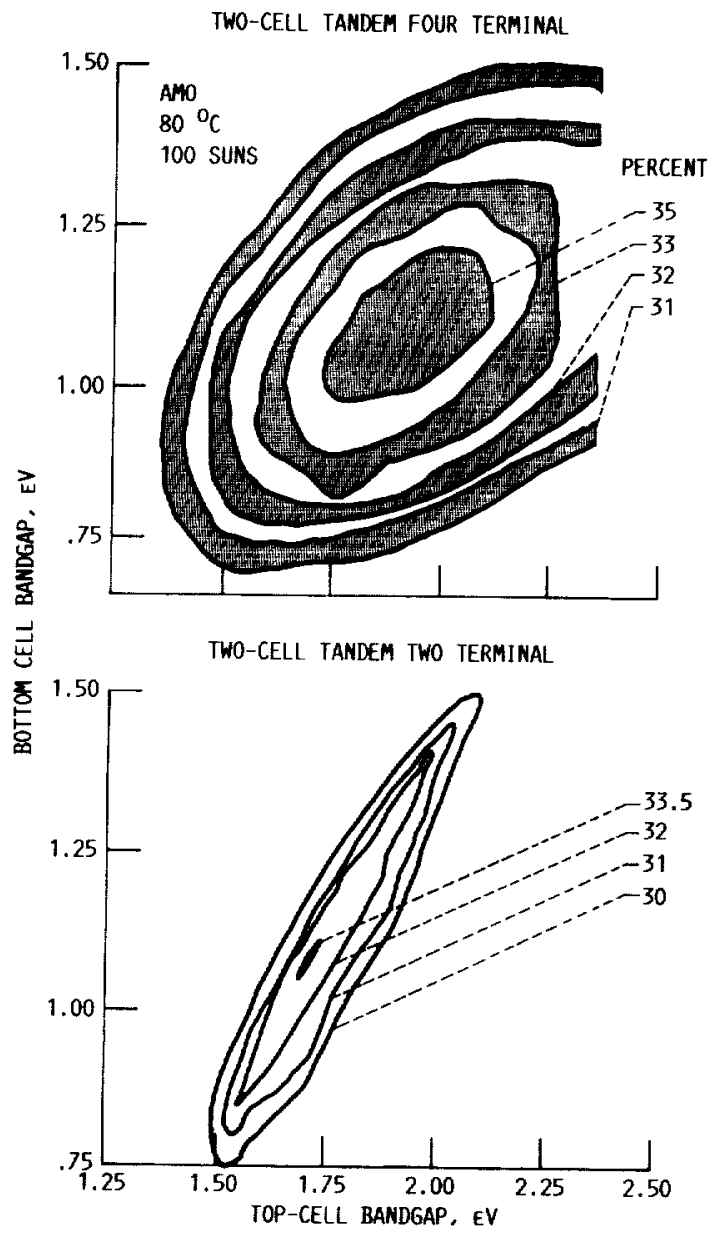

FIGURE 9, - ISO - EFFICIENCY CURVES. 


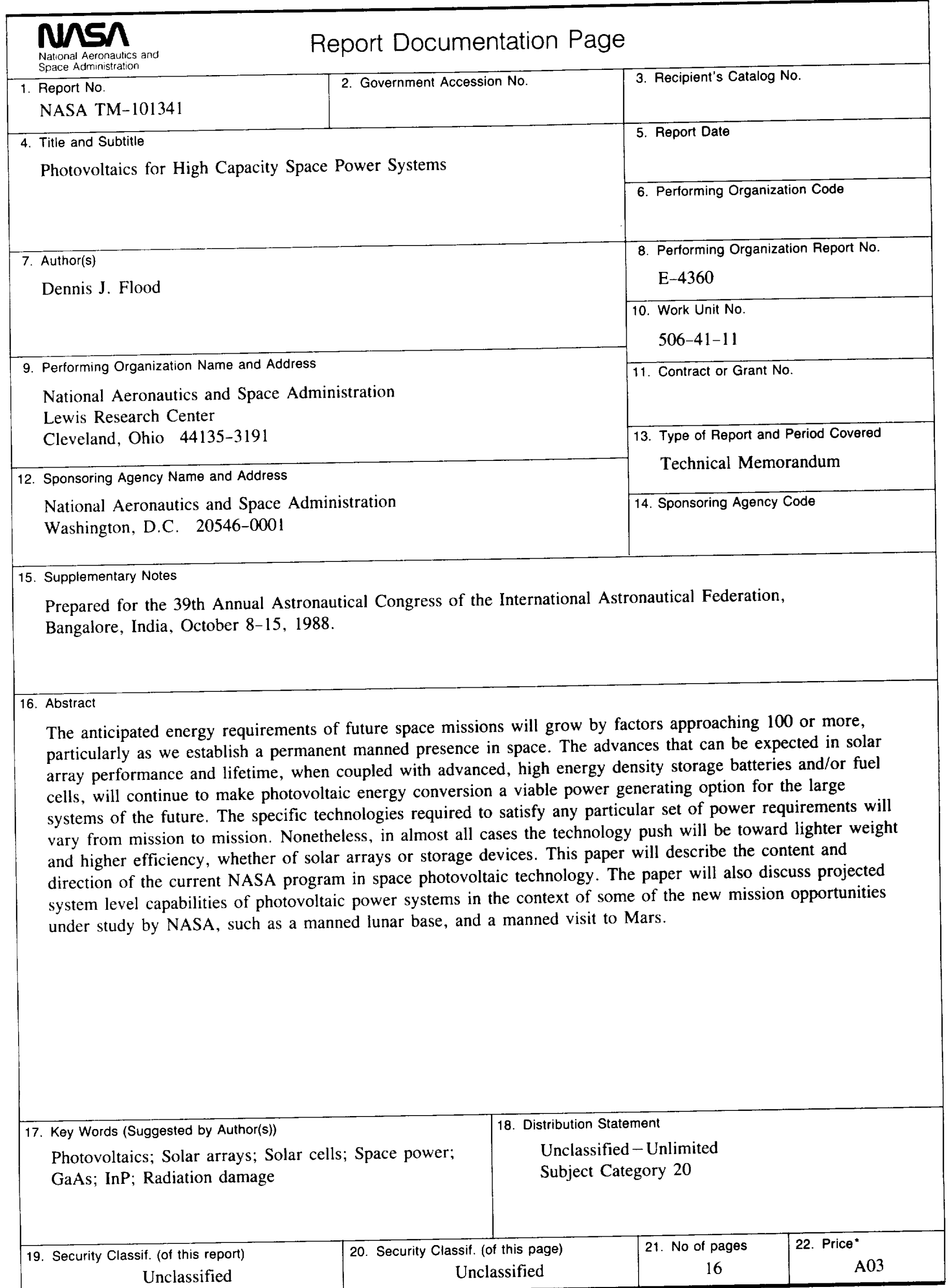




$$
\begin{array}{llll}
- & - & \square & \square
\end{array}
$$



National Aeronautics and

Space Administration

Lewis Research Center

Cleveland, Ohio 44135

Otticial Business

Penatty for Private Use $\$ 300$
FOURTH CLASS MAIL

ADDRESS CORRECTION REQUESTED

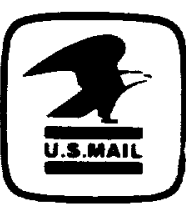

Postage and F tes Par

Natmont Aeromatulks and

Spites Autrimitralum

NAin $45:$ 